\title{
Comparison of two data collection processes in clinical studies: electronic and paper case report forms
}

Anaïs Le Jeannic ${ }^{1}$, Céline Quelen ${ }^{1}$, Corinne Alberti ${ }^{2,3^{*}}$, Isabelle Durand-Zaleski ${ }^{1,4}$, on behalf of the CompaRec Investigators

\begin{abstract}
Background: Electronic Case Report Forms (eCRFs) are increasingly chosen by investigators and sponsors of clinical research instead of the traditional pen-and-paper data collection (pCRFs). Previous studies suggested that eCRFs avoided mistakes, shortened the duration of clinical studies and reduced data collection costs.

Methods: Our objectives were to describe and contrast both objective and subjective efficiency of pCRF and eCRF use in clinical studies. A total of 27 studies (11 eCRF, 16 pCRF) sponsored by the Paris hospital consortium, conducted and completed between 2001 and 2011 were included. Questionnaires were emailed to investigators of those studies, as well as clinical research associates and data managers working in Paris hospitals, soliciting their level of satisfaction and preferences for eCRFs and pCRFs. Mean costs and timeframes were compared using bootstrap methods, linear and logistic regression.

Results: The total cost per patient was $374 € \pm 351$ with eCRFs vs. 1,135€ $\pm 1,234$ with pCRFs. Time between the opening of the first center and the database lock was 31.7 months Q1 = 24.6; Q3 = 42.8 using eCRFs, vs. 39.8 months $\mathrm{Q} 1=31.7 ; \mathrm{Q} 3=52.2$ with pCRFs $(p=0.11)$. Electronic CRFs were globally preferred by all (31/72 vs. 15/72 for paper) for easier monitoring and improved data quality.

Conclusions: This study found that eCRFs and pCRFs are used in studies with different patient numbers, center numbers and risk. The first ones are more advantageous in large, low-risk studies and gain support from a majority of stakeholders.
\end{abstract}

Keywords: Electronic data collection, Costs, Time management, Work satisfaction

\section{Background}

Collection of individual patient data on Case Report Forms (CRFs) in clinical research has traditionally been done by investigators in their offices summarizing medical charts on paper forms (pCRFs), a tedious method that could result in data errors and wrong conclusions $[1,2]$. Electronic data capture has in recent years been increasingly used in both industry and academic research settings $[3,4]$. The feasibility of electronic CRFs (eCRFs) has been documented by numerous studies analyzing

\footnotetext{
* Correspondence: corinne.alberti@inserm.fr

${ }^{2}$ AP-HP, Hôpital Robert Debré, Unité d'Épidémiologie clinique, Groupe Hospitalier Robert Debré, 48, Bld Sérurier, F-75019 Paris, France

${ }^{3}$ Université Paris Diderot, PRES Sorbonne Paris Cité, F-75019 Paris, France

Full list of author information is available at the end of the article
}

data collected on websites, laptops or digital pens [5-10]. Since the mid-1980s, eCRFs have increased data quality and completeness by using alarms, automatic completions and reminders $[11,12]$, reducing losses and transport logistics, especially for multicenter trials [13]. Moreover, use of eCRFs permits speedier database processing and shorter study periods, resulting in lower costs [7,11,14-19]. Previous studies of eCRFs have primarily focused on the investigators' point of view, while few have documented the perspectives of the other stakeholders $[5,6,20,21]$.

Despite their demonstrated usefulness, eCRFs have not become dominant [3]. Welker has identified some of the barriers to their dissemination: the lack of available onsite technology, insufficient assistance by Information Technologies staff or software providers, investigators'

\section{Biomed Central}


lack of motivation and interference of eCRFs with their clinical tasks, complexity of installation and maintenance of the software and high investment cost [22]. The labor cost of data entry is transferred from clerks to investigators who may see few tangible benefits apart from a better quality of data and speedier study completion. While some investigators have integrated the electronic interface into their medical practice to the point of making it an asset [23], the majority views the implementation of an eCRF in a paper-based working environment as a source of redundancy $[19,24]$.

Our objective was to formally describe the efficiency (measured by satisfaction, cost and duration of the study) of electronic and paper CRFs in the context of biomedical research conducted in hospitals.

\section{Methods}

The primary endpoint was the satisfaction of stakeholders in a clinical study: investigators, clinical research associates (CRAs) and data managers (DMs). Secondary endpoints were costs and duration of the studies. Our hypotheses were that eCRFs save cost and time $[18,22]$, and would be preferred by those 3 stakeholders [5].

\section{Material}

\section{Clinical studies: inclusion criteria}

We retrospectively selected biomedical research studies monitored by 6 research units involved in eCRF testing, completed between 2007 and 2010 (or 2011 for eCRFs) and sponsored by the Paris regional hospital consortium AP-HP. The research topics were representative of the ongoing publicly funded clinical research. Paper (p) CRF studies were defined by the use of a CRF on paper, completed with a pen, and data entry by a data clerk. Electronic (e) CRF studies used computer data entry by the investigator or an assistant, online or offline. Two studies which used pCRFs to collect data before entering it in the eCRF were analyzed in the eCRF group.

\section{Stakeholders}

We investigated the satisfaction and preference of three stakeholder groups: investigators, clinical research associates (CRAs) and data managers (DMs) for both types of CRF. The investigators surveyed had included patients in the studies selected, belonged to 45 different hospitals and were primarily physicians or nurses; the CRAs and DMs were working for the Paris regional hospital consortium.

\section{Methods}

\section{Clinical studies}

We collected protocols, budgets and expense statements, CRFs, monitoring reports and other relevant technical documents. Studies were characterized by phase, number of patients, purpose (therapeutic/ diagnostic/observational), geographical level and risk (from level $\mathrm{A}=$ minimal, e.g. trial involving only additional blood sample collection, to $\mathrm{D}=$ major risk, e.g. trial of innovative therapies, phase I or II trials). We estimated the duration of patients' recruitment, the time between the opening of the first center and the database lock, and between the last visit of the last patient and the database lock (see Additional file 1).

\section{Cost estimation}

The cost of a study was estimated from: labor costs, i.e. expenditures for CRAs and DMs salaries during the study, and logistical costs, i.e. printing of paper CRFs, development of database and interface if done by an external company, cost of the eCRF, travel costs of CRAs and investigators, and randomization software. Since 2003, following a successful tender by TELEMEDICINE Technologies S.A.S., the AP-HP's Department of Clinical Research and Development (Direction de la Recherche Clinique et du Développement; DRCD) has contracted with TELEMEDICINE for use of the software CleanWEB in eCRFs for clinical trials. In 2010, the global cost was $861.12 €$ for a trial with one or two centers and 9,687.60€ for three or more centers $(1 €=$ US $\$ 1.33)$. We used the 2010 contract prices for the cost of each eCRF. Expenditures were updated to 2010 with the hypothesis that they were completed during the median year for studies lasting longer than a year. We estimated both the total cost and the cost per patient.

\section{Stakeholders' satisfaction}

Satisfaction of the three stakeholder groups was measured through surveys (see Additional files 2, 3 and 4). Each stakeholder received their own questionnaire, consisting of demographics, closed-ended questions about satisfaction, preferences and self-reported usage patterns. The last part consisted of two open-ended questions to identify additional issues.

\section{Statistical analysis \\ Clinical studies}

The unit of analysis was the study. Studies using pCRFs and eCRFs were compared by characteristics (phase, number of patients and risk), costs and timeframes. Fisher's exact test was used for categorical variables and Wilcoxon sign-rank test for continuous ones. Due to the skewed distribution of costs and the sample size, costs per patient of pCRFs and eCRFs were compared using the biascorrected and accelerated bootstrap (BCa) procedure with 2,000 replications to estimate the confidence interval [25]. We used a linear regression model to explain costs per patient and time between the opening of the first center and the freezing of the database. A log transformation was used to analyze costs per patient. The linear regression models included terms for data collection method (pCRF/ 
eCRF), randomization, geographical area (regional/national), level of risk, number of patients, number of centers and number of variables, time from the opening of the first center to database lock. The regression models did not include the phase of the study which was highly correlated with patient numbers and would not have added extra information. A forward stepwise method was used, and the variable "pCRF/eCRF" was forced in the

Table 1 Characteristics of the studies $(n=27)$

\begin{tabular}{|c|c|c|c|c|}
\hline & & pCRFs $n=16$ & eCRFs $n=11$ & All $n=27$ \\
\hline \multirow[t]{2}{*}{ Design } & Non-interventional studies & $1(6 \%)$ & $4(36.4 \%)$ & $5(18.5 \%)$ \\
\hline & Clinical trials & 15 (94\%) & $7(63.6 \%)$ & $22(81.5 \%)$ \\
\hline Randomized & & $10(63 \%)$ & 7 (64\%) & $17(63 \%)$ \\
\hline Multicenter & & $10(63 \%)$ & $9(82 \%)$ & 19 (70\%) \\
\hline \multirow[t]{2}{*}{ Geographic level } & International/national & $7(44 \%)$ & $8(73 \%)$ & $15(56 \%)$ \\
\hline & Regional & $9(56 \%)$ & $3(27 \%)$ & $12(44 \%)$ \\
\hline \multirow[t]{3}{*}{ Purpose* } & Diagnostic & $1(6 \%)$ & $3(27 \%)$ & $4(15 \%)$ \\
\hline & Observational & $0(0 \%)$ & $2(18 \%)$ & $2(7 \%)$ \\
\hline & Therapeutic & 15 (94\%) & $6(55 \%)$ & $21(78 \%)$ \\
\hline \multirow[t]{4}{*}{ Risk level $^{\alpha}$} & A & $2(13 \%)$ & $4(36.4 \%)$ & $6(22 \%)$ \\
\hline & B & $4(25 \%)$ & $3(27 \%)$ & $7(26 \%)$ \\
\hline & $\mathrm{C}$ & $3(19 \%)$ & $3(27 \%)$ & $6(22 \%)$ \\
\hline & D & 7 (44\%) & $1(9 \%)$ & $8(30 \%)$ \\
\hline \multirow[t]{4}{*}{ Clinical trial phase } & 1 & $1(7 \%)$ & $0(0 \%)$ & $1(4 \%)$ \\
\hline & 2 & $4(27 \%)$ & $1(14 \%)$ & $5(23 \%)$ \\
\hline & 3 & $7(47 \%)$ & $6(86 \%)$ & $13(59 \%)$ \\
\hline & 4 & $3(20 \%)$ & $0(0 \%)$ & $3(14 \%)$ \\
\hline \multirow[t]{3}{*}{ Median number of patients included* } & & 60 & 355 & 80 \\
\hline & & $\mathrm{Q} 1=27$ & $\mathrm{Q} 1=78$ & $\mathrm{Q} 1=50$ \\
\hline & & $\mathrm{Q} 3=141$ & $\mathrm{Q} 3=700$ & $\mathrm{Q} 3=500$ \\
\hline \multirow[t]{3}{*}{ Median number of centers } & & 5 & 10 & 7 \\
\hline & & $\mathrm{Q} 1=1$ & $\mathrm{Q} 1=6$ & $\mathrm{Q} 1=1$ \\
\hline & & $\mathrm{Q} 3=10$ & $\mathrm{Q} 3=13$ & $\mathrm{Q} 3=12$ \\
\hline \multirow[t]{3}{*}{ Median planned duration of study (months) } & & 24 & 27 & 25 \\
\hline & & $\mathrm{Q} 1=16$ & $\mathrm{Q} 1=18$ & $\mathrm{Q} 1=16$ \\
\hline & & $\mathrm{Q} 3=40$ & $\mathrm{Q} 3=36$ & $\mathrm{Q} 3=36$ \\
\hline \multirow[t]{3}{*}{ Median planned patient follow up (days) } & & 137 & 60 & 91 \\
\hline & & $\mathrm{Q} 1=67$ & $\mathrm{Q} 1=12$ & $\mathrm{Q} 1=30$ \\
\hline & & $\mathrm{Q} 3=365$ & $\mathrm{Q} 3=112$ & $\mathrm{Q} 3=213$ \\
\hline \multirow[t]{3}{*}{ Median number of variables in CRF } & & 1,062 & 396 & 1011 \\
\hline & & $\mathrm{Q} 1=669$ & $\mathrm{Q} 1=153$ & $\mathrm{Q} 1=286$ \\
\hline & & $\mathrm{Q} 3=1,118$ & $\mathrm{Q} 3=1,567$ & $\mathrm{Q} 3=1,126$ \\
\hline \multirow[t]{3}{*}{ Median number of variables in database ${ }^{\beta}$} & & 65,928 & 304,929 & 76,692 \\
\hline & & $\mathrm{Q} 1=18,764$ & $\mathrm{Q} 1=35,250$ & $\mathrm{Q} 1=20,088$ \\
\hline & & $\mathrm{Q} 3=171,646$ & $\mathrm{Q} 3=625,865$ & $\mathrm{Q} 3=304,929$ \\
\hline \multirow[t]{3}{*}{ Median number of full pages in CRF* } & & 39 & 17 & 31 \\
\hline & & $\mathrm{Q} 1=28$ & $\mathrm{Q} 1=9$ & $\mathrm{Q} 1=17$ \\
\hline & & $\mathrm{Q} 3=44$ & $\mathrm{Q} 3=30$ & $\mathrm{Q} 3=44$ \\
\hline
\end{tabular}

*Significant difference between eCRFs and pCRFs $(p<0.05)$.

${ }^{a}$ From level $A=$ minimal, e.g. trial involving only additional blood sample collection, to $D=$ major risk, e.g. trial of innovative therapies, phase I or II trials.

${ }^{\beta}$ Number of variables in database $=$ number of patients $x$ number of variables in CRF. 
models. Finally, a logistic model was used to explain the choice of pCRF/eCRF. The model included randomization, geographical area, level of risk of the study, number of patients included, number of centers, number of variables, duration and number of medical teams involved [18].

\section{Stakeholders' satisfaction}

The unit of analysis was the respondent. Descriptive statistics were performed on the answers of investigators, CRAs and DMs. Global satisfaction of stakeholders was compared using a Chi square test. Multinomial and basic logistic regression models were used to understand satisfaction and preferences, with the hypotheses that CRAs, DMs and youngest stakeholders should prefer eCRFs; models included type of stakeholder, age, sex, level of computer proficiency and research experience.

Answers to the two open-ended questions were classified by topic using word clustering for the question about key features of an optimal data collection form, and by topic clustering for the open remarks.

All analyses were performed using SAS ${ }^{\circ}$ (Version 9.3 for Windows, SAS Institute, Inc., Cary NC, USA).

\section{Results}

We included 27 clinical studies, 16 (59\%) using pCRFs and $11(41 \%)$ eCRFs.

The main characteristics of the studies are summarized in Table 1. Electronic CRFs studies were mostly large multicenter, national and phase 3 clinical trials while pCRFs studies were trials with few patients and centers. The majority of pCRFs were drug trials $(15 / 16 ; \mathrm{p}=0.036)$, and eCRFs were more often used in trials with a significantly higher number of patients ( 355 vs. 60 patients in pCRFs; $\mathrm{p}=0.014)$ and fewer data (17 vs. 39 pages with pCRFs; $\mathrm{p}=0.027$ ). The number of patients was the only explanatory variable for CRF choice (Table 2).

\section{Clinical studies}

Time from the opening of the first center to database lock tended to be shorter with eCRFs (31.7 months vs. 39.8 months; $\mathrm{p}=0.11$ ). We found no difference in the average duration of recruitment $(22.4 \pm 9$ months with eCRFs vs. $26.5 \pm 13$ months with $\mathrm{pCRFs}$; $\mathrm{p}=0.34$ ) nor in time from the last visit of the last patient to database freeze (8 months with eCRFs vs. 8.8 months with pCRFs; $\mathrm{p}=0.81$ ). Linear regression found that the use of eCRF and the smaller number of centers were associated with shorter study durations (Table 3 ).

The total average cost of a trial was higher with eCRFs $(88,222 € \pm 47,907)$ than with pCRFs $(58,794 € \pm 48,665)$, but the mean cost per patient was lower with eCRFs ( $374 € \pm 351$ vs. $1,135 € \pm 1,234$ ) (Figure 1 ). The difference
Table 2 Logistic regression model with data collection method as dependant variables $(n=27)$

\begin{tabular}{|c|c|c|c|c|}
\hline & & OR & IC & $p$ \\
\hline \multirow[t]{2}{*}{ Geographic level } & $\begin{array}{l}\text { International/ } \\
\text { national }\end{array}$ & 1 & - & 0.14 \\
\hline & Regional & 0.292 & $0.056-1.525$ & \\
\hline \multirow[t]{4}{*}{ Risk level } & A & 1 & - & 0.28 \\
\hline & B & 0.375 & $0.039-3.605$ & \\
\hline & $\mathrm{C}$ & 0.500 & $0.049-5.154$ & \\
\hline & D & 0.071 & $0.005-1.059$ & \\
\hline $\begin{array}{l}\text { Number of patients } \\
\text { included }\end{array}$ & & 1.004 & $1.000-1.009$ & 0.04 \\
\hline Number of centers & & 1.004 & $0.963-1.047$ & 0.85 \\
\hline Number of variables & & 0.999 & $0.998-1.000$ & 0.23 \\
\hline $\begin{array}{l}\text { Planned duration of } \\
\text { study }\end{array}$ & & 0.987 & $0.928-1.050$ & 0.68 \\
\hline $\begin{array}{l}\text { Number of medical } \\
\text { teams involved }\end{array}$ & & 0.936 & $0.369-2.374$ & 0.89 \\
\hline
\end{tabular}

The modeled probability is the choice of an eCRF for the study as opposed to a pCRF.

in average cost per patient was $762 €$ per patient $(95 \% \mathrm{CI}$ bootstrap: $[270 €-1613 €])$. Other explanatory variables were the design of the study - phase 1 and 2 trials without randomization being more expensive - and the number of patients included, but not the number of variables collected (Table 3).

Table 3 Linear regression model with cost log and duration as dependant variables $(n=27)$

\begin{tabular}{|c|c|c|c|c|}
\hline & & $\begin{array}{c}\text { Parameter } \\
\text { estimate }\end{array}$ & SE & $P$ value \\
\hline \multicolumn{5}{|l|}{$\begin{array}{l}\text { Duration of the } \\
\text { study: }\end{array}$} \\
\hline \multirow[t]{2}{*}{$\mathrm{CRF}^{*}$} & Paper & - & - & 0.045 \\
\hline & Electronic & -10.14 & 4.79 & \\
\hline $\begin{array}{l}\text { Participating } \\
\text { centers* }\end{array}$ & & 0.48 & 0.13 & 0.001 \\
\hline \multicolumn{5}{|l|}{$\begin{array}{l}\text { Cost of the study } \\
\text { (log): }\end{array}$} \\
\hline \multirow[t]{2}{*}{ CRF } & Paper & - & - & 0.41 \\
\hline & Electronic & 0.29 & 0.35 & \\
\hline \multirow[t]{3}{*}{ Design* } & $\begin{array}{l}\text { Trial without } \\
\text { randomization }\end{array}$ & - & - & 0.002 \\
\hline & $\begin{array}{l}\text { Trial with } \\
\text { randomization }\end{array}$ & -1.33 & 0.40 & \\
\hline & $\begin{array}{l}\text { Non-interventional } \\
\text { study }\end{array}$ & -2.51 & 0.62 & \\
\hline $\begin{array}{l}\text { Number of } \\
\text { patients included* }\end{array}$ & & -0.001 & 0,0004 & 0.021 \\
\hline
\end{tabular}

SE: standard error.

*Explanatory variable $(p<0.05)$. 


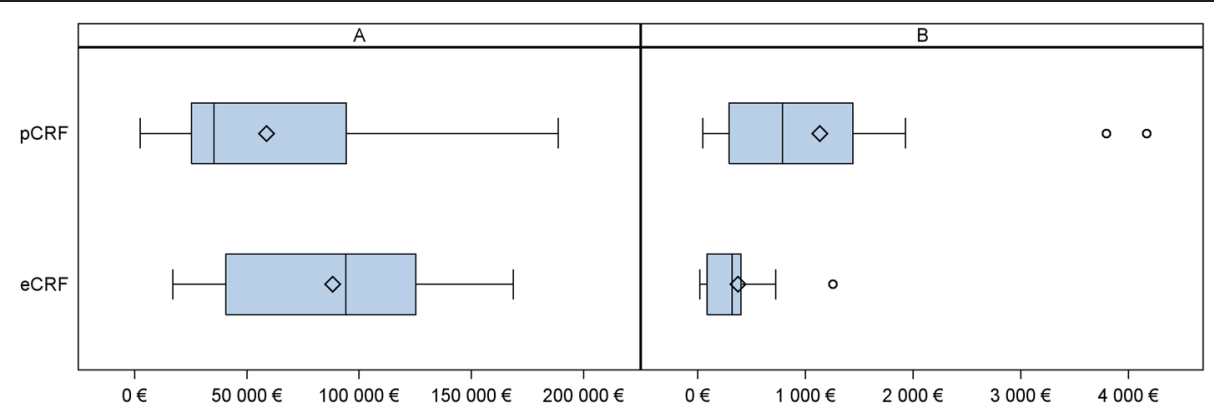

Figure 1 Cost of the studies by data collection method. A: Total cost; B: Total cost per patient.

\section{Stakeholders' satisfaction}

Thirty-four questionnaires were returned from investigators, including six from centers outside Paris. Forty-one questionnaires were returned from CRAs and 17 from DMs. Seven investigators declined to participate because of a lack of experience with eCRFs, and 2 CRAs because of a lack of time (Figure 2). Among the 34 answering investigators, 33 had experienced pCRFs, 29 eCRFs and 28 had experienced both and responded to comparison questions. The main characteristics of the respondents are summarized in Table 4.

Overall, stakeholders were as satisfied with eCRFs as with pCRFs $(51 / 76$ vs. $58 / 86 ; \mathrm{p}=0.96)$ (Figure 3$)$. When asked for their preference of one over the other, a majority of stakeholders chose eCRF (Figure 4).

Half of investigators (16/29) adapted to the eCRF user interface from the first patient. Half of them (15/29) experienced technical problems from time to time with eCRFs, and those were usually resolved within a day (23/29). One-third (10/29) was upset by the presence of immediate checks and constraints in the eCRF, while most (23/29) enjoyed the lack of constraints in a pCRF. Two-thirds of investigators $(18 / 29)$ were satisfied with the intuitiveness of the eCRF interface. Twenty / 29 investigators never entered data in the eCRF during consultations, while 15/33 did so when using a pCRF. Half (16/33) were satisfied that the pCRF did not affect or affected positively the patientdoctor relationship, while a majority (17/29) had no opinion on the impact of the eCRF. Data entry was found easier with pCRF (13/28 vs. $11 / 28)$. Nonetheless, investigators were more satisfied (24/29 vs. 9/33) with the logistics, storage and data safety of eCRFs. Finally, most investigators $(24 / 29)$ would accept an eCRF in the future while only half (17/33) would use a pCRF.

Most CRAs preferred the eCRF (Figure 3), and one-third would choose a CRF depending on the trial characteristics. CRAs reported preference for pCRFs in monocentric trials including few patients while they would rather use an eCRF for a multicentric trial unless there were few patients and variables. Despite their preference for eCRFs, CRAs identified the following benefits of pCRFs: the greater acceptability by investigators, the tangibility of paper and the impetus to spend time in the centers to monitor the data collection. They based their preference for eCRFs on the

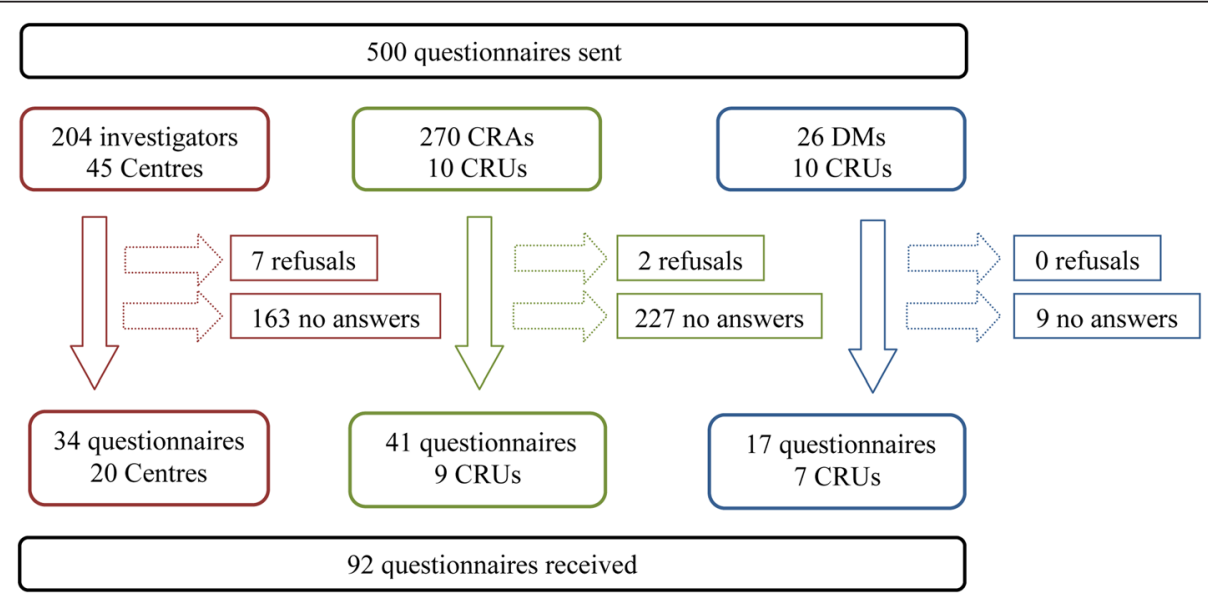

Figure 2 Questionnaires flow-chart. $C R A=$ clinical research associate, $D M=$ data manager, $C R U=c l i n i c a l$ research unit. 
Table 4 Characteristics of the respondents to the satisfaction and preference surveys

\begin{tabular}{|c|c|c|c|c|}
\hline & & Investigators & CRAs & DMs \\
\hline Respondent & & 34 & 41 & 17 \\
\hline \multirow[t]{3}{*}{ Age } & $<30$ & $0(0 \%)$ & $17(42 \%)$ & $7(44 \%)$ \\
\hline & 30 to 40 & $8(24 \%)$ & $19(46 \%)$ & $7(44 \%)$ \\
\hline & $>40$ & $26(76 \%)$ & $5(12 \%)$ & $2(12 \%)$ \\
\hline \multirow[t]{2}{*}{ Gender } & M & $20(59 \%)$ & $6(15 \%)$ & $10(59 \%)$ \\
\hline & $\mathbf{F}$ & $14(41 \%)$ & $35(85 \%)$ & $7(41 \%)$ \\
\hline \multirow[t]{3}{*}{ Computer proficiency level } & Beginner & $1(3 \%)$ & - & - \\
\hline & Average & $19(56 \%)$ & - & - \\
\hline & Good & $14(41 \%)$ & - & - \\
\hline \multirow[t]{4}{*}{ Clinical research experience } & $<1$ year & - & $4(10 \%)$ & $2(12 \%)$ \\
\hline & 1 to 3 years & - & $19(46 \%)$ & $7(41 \%)$ \\
\hline & 3 to 5 years & - & $11(27 \%)$ & $3(18 \%)$ \\
\hline & $>5$ years & - & $7(17 \%)$ & $5(29 \%)$ \\
\hline
\end{tabular}

CRA: clinical research associate, DM: data manager.

more effective monitoring which allowed them to monitor data collection from their offices - for example by receiving queries of abnormal entries in real time-, the better prevention of errors resulting from it and from automatic checks, the easier electronic storage (as opposed to the copious paper storage of pCRFs) and a greater efficiency in managing drug supplies.

DMs preferred eCRFs (Figure 3) because fewer queries were generated and the database contained fewer errors before cleaning. Thus they saved time and allowed faster data availability.

No variable was associated significantly with satisfaction or preference. The following trends appeared: women (DMs and CRAs) were likely to prefer eCRF, younger and computer-proficient investigators were likely to be dissatisfied by eCRF, and stakeholders with a greater pCRF experience ( $>10$ clinical studies) were likely to prefer pCRF (see Additional file 5 and Additional file 6).

The requirements of an optimal data collection are summarized in Table 5: "eCRFs would be perfect at 100\% if we could have the computer next to the patient". Additional issues are summarized in Table 6.

\section{Discussion}

In this first description of the use of eCRFs and pCRFs across 27 clinical studies, we found that most stakeholders were satisfied with eCRFs and that the use of

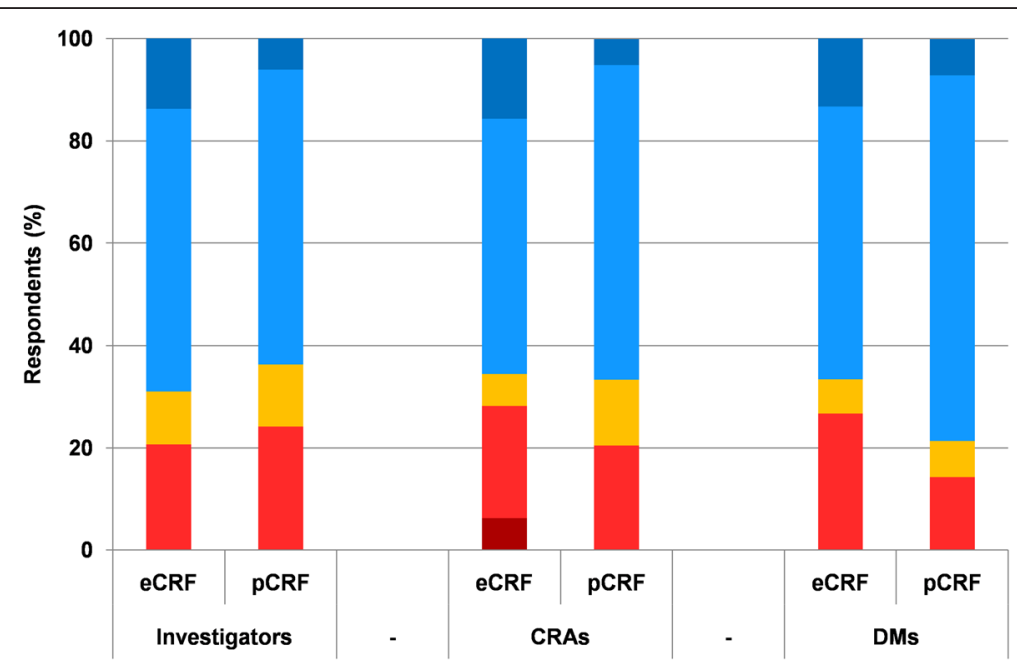

Figure 3 Satisfaction of respondents regarding eCRF and pCRF data collection. Percentage of satisfaction level for the 3 stakeholders

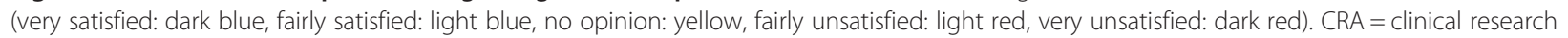
associate, $\mathrm{DM}=$ data manager. 


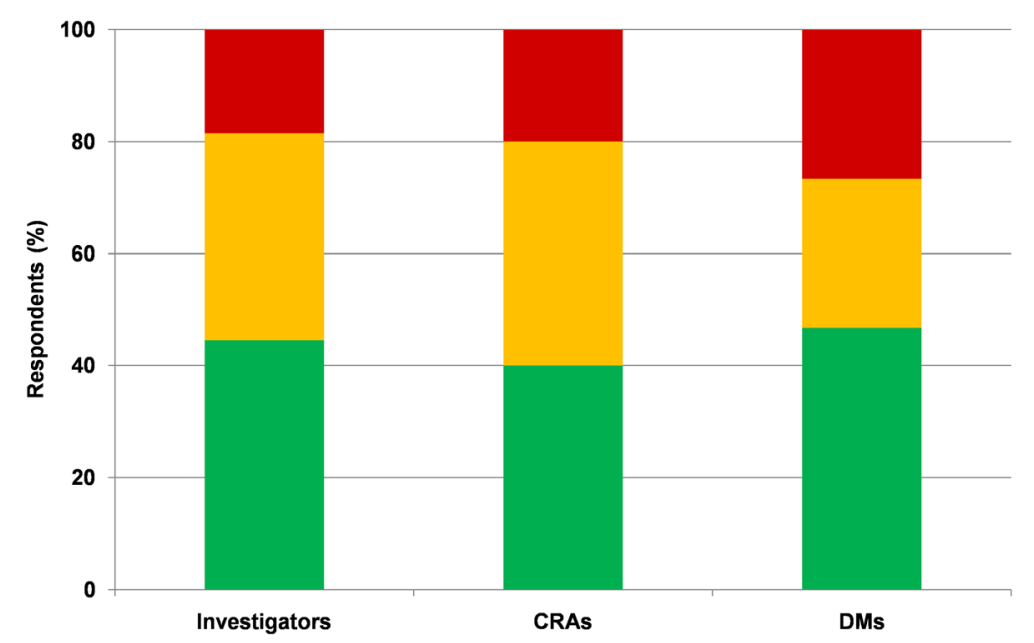

Figure 4 Preferences of respondents between eCRF and pCRF data collection. Percentage of stakeholders preferring pCRF (red), with no or mixed opinion (yellow) or preferring eCRF (green). CRA = clinical research associate, DM= data manager.

eCRFs was associated with shorter study duration and lower cost per patient. Average duration of recruitment did not differ between pCRF and eCRF studies, despite a greater number of trials investigating rare and pediatric conditions in the pCRF group.

Data managers reported that eCRFs saved time and improved data quality, however we cannot exclude that the perception of fewer queries simply results from a smaller number of variables monitored; clinical research associates valued the automated quality checks and easier storage of electronic data. Both DMs and CRAs preferred eCRF for multicenter trials. Improvements are needed to facilitate the integration of eCRFs into clinical practice, including widespread adoption of portable devices such as digital pens [6] or graphic tablets, which one investigator described as "the solution for the future, and already used very successfully in anesthesia".

It appeared that stakeholders' characteristics do not predict preferences, except for young and computer literate investigators who tended to be more demanding with eCRFs, probably because they had greater expectations of eCRF and yet were more aware of its limitations.

In addition to exploring stakeholder perspectives, we found that eCRFs were mainly used in large, national and

Table 5 "What are the key features of an optimal data collection method in a clinical study?"

\begin{tabular}{|c|c|c|}
\hline & Main features answered & Details \\
\hline \multirow[t]{3}{*}{ Investigators } & Quality interface (x23) & Fast, simple, without bugs and blocking, with flexible data entry \\
\hline & Reliable data collection, with few queries (x8) & Alarms and mandatory fields \\
\hline & Electronic format $(\times 3)$ & Allowing data sharing without data recapture and duplication \\
\hline \multirow[t]{6}{*}{ CRAs } & Quality interface (x24) & Fast, simple, without bugs and blocking, with flexible data entry \\
\hline & Accessible form (x7) & \\
\hline & Efficient monitoring $(x 5)$ & Real-time queries and remote consultations \\
\hline & Quality of form (x5) & No free answers, short and clear questions and few variables \\
\hline & Immediate controls during data entry (x3) & \\
\hline & Motivation and availability of investigators (x3) & \\
\hline \multirow[t]{6}{*}{ DMs } & Reliable data collection, few queries (x17) & Controls and constraints during data entry and queries emailed automatically \\
\hline & Quality of database, easy to operate (x5) & \\
\hline & Quality of form (x5) & Real-time queries and remote consultations \\
\hline & Quality of form (x5) & No free answers, short and clear questions and few variables \\
\hline & Quality interface (x3) & Ergonomic \\
\hline & Maximum access fees and free action for data managers ( $x 2)$ & \\
\hline
\end{tabular}




\section{Table 6 Main themes discussed by stakeholders in open-ended questions}

\begin{tabular}{|c|c|c|}
\hline \multirow[t]{5}{*}{ Investigators } & \multirow[t]{3}{*}{ Complaints } & $\begin{array}{l}\text { About redundancy of data "It doesn't matter whether it's on paper or electronic, as long as data are } \\
\text { entered only once." }\end{array}$ \\
\hline & & $\begin{array}{l}\text { That some promoters want them to complete a pCRF first as source document and then to re-enter all } \\
\text { the data in the eCRF. }\end{array}$ \\
\hline & & $\begin{array}{l}\text { About software design companies "By trying to make money, firms that sell this type of CRF software } \\
\text { developed templates that do not fit well with the variability of studies and data." }\end{array}$ \\
\hline & \multirow[t]{2}{*}{ Hopes } & $\begin{array}{l}\text { To have their needs taken into account "eCRFs are developed by those who use data but never by } \\
\text { those who enter the data and who have, in the present context, less and less availability." }\end{array}$ \\
\hline & & $\begin{array}{l}\text { Working with transportable computers "The graphic tablet, an eCRF transportable to the bedside, is the } \\
\text { solution for future. It's already used in anesthesia with great success." }\end{array}$ \\
\hline \multirow[t]{2}{*}{ CRAs } & \multirow[t]{2}{*}{ Complaints } & CTAs needed on site: "Whatever the collection method, investigators don't have the time ..." \\
\hline & & eCRF storage: CRFs still needs to be kept on paper, as source data and to be signed ... \\
\hline \multirow[t]{3}{*}{ DMs } & \multirow[t]{3}{*}{$\begin{array}{l}\text { Complaints about CleanWEB } \\
\text { consistency management }\end{array}$} & $\begin{array}{l}\text { "Only simple checks can be defined in CleanWEB; more complicated ones must be programmed in SAS } \\
\text { after database export." }\end{array}$ \\
\hline & & Moreover, "the computer code managing the automatic controls should be accessible and easily understood." \\
\hline & & $\begin{array}{l}\text { "The database structure isn't known when designing eCRFs for CleanWEB, yet it is the first thing that } \\
\text { must be established. And it's currently impossible to have a structure that complies with CDISC." }\end{array}$ \\
\hline
\end{tabular}

Answers from investigators, clinical research associates and data managers.

CRA: clinical research associate, DM: data manager.

multicenter trials, whereas pCRFs were used in small high risk drug trials, possibly because of the greater reliability of written documents.

The few studies investigating stakeholders' experiences of CRFs have mostly focused on investigators and found a high level of support for eCRFs [24]. We included two additional key stakeholders and revealed more mixed results in the level of satisfaction and preferences regarding eCRFs. CRAs agreed with the Litchfield hypothesis [5] that monitoring would be more efficient with an eCRF. Moreover, as expected [17,26], acceptance of eCRFs by investigators remained one of their biggest challenges. López-Carrero reported very positive reviews of eCRFs by investigators, with three-quarters finding data entry easier and more than a half saying that it decreased workload. We did not find investigators to be so optimistic about eCRF capacities, particularly with respect to data entry and workload. The fact that the López-Carrero [21] investigators were asked about a pilot project with a "specifically designed" eCRF may explain our less enthusiastic responses.

While literature reviews have found favorable results for eCRFs in terms of study duration and costs, we found that the lower cost per patient was explained by the large patient number in eCRF trials. This may be attributable to our sample which did not include pCRF studies with large patient numbers, or eCRF studies with small patient numbers and/or to the fact that most of the other cost studies were based on models [18] or used ad-hoc prototypes $[27,28]$.

The retrospective non randomized design of our study was dictated by two major issues: time constraints and acceptability. Randomization would not have been acceptable to investigators who want to be able to make their own choices and it also would not have been able to show that eCRF and pCRF have their specific indications and are not therefore perfect substitutes. There is a kind of 'indication bias' as shown both in Table 1 and in the stakeholders' responses. Indeed we have shown that for some studies pCRF is cheaper and appears more trustworthy. In addition, unobserved factors must also influence the choice between eCRF and pCRF as can be assumed by, for example, the fact that the large difference in the number of variables between the 2 collection methods was not correlated to any of the characteristics of the studies that we investigated.

Whilst the CRA and Investigator questionnaires response rates were low, due to many stakeholders having changed institutions and no longer being locatable, they emanated from 9/10 AP-HP units and 20 different hospitals spread over the French territory. Our small sample of respondents is mirrored in other studies, López-Carrero et al. [21] had a similar problem with only 27 investigators answering from 33 centers, and Lium et al. [24] interviewed 18 physicians, but from only 2 centers.

Most clinical trials sponsored by the AP-HP currently use CleanWEB for eCRFs. As a result, the stakeholders' answers were related to that software. Our results may not adequately reflect the current situation of eCRF since half of the studies using eCRFs had started between 2004 and 2006 and are not representative of the current capacities of electronic data capture. Recent adaptations of CleanWEB include certification with Clinical Data Interchange Standards Consortium CDISC, 
the possibility to connect to the server on-line or enter data off-line and direct data export to SAS, which may improve future satisfaction with eCRFs.

We were unable to suggest a financial advantage in using eCRFs in trials with fewer than 50 patients, given that the smallest eCRF trial had 47 patients. Nonetheless, CleanWEB price discounts for monocentric eCRFs could make it cost-efficient, even for small trials. Likewise, we were not able to draw any conclusions regarding pCRF trials with more than 700 patients. We did not take into account the annual maintenance package of $125,580 €$, billed to the institution for all studies using CleanWEB. We used bootstrap replications for the cost analysis because of the small number of studies and because calculation of means after log transformation resulted in a comparison of geometric mean costs instead of arithmetic means. The bootstrap method requires the true distribution of the data to be adequately represented by its empirical distribution [25]. Finally, as we did not select the studies based on their characteristics, we had much heterogeneity in terms of risk level and trial phase.

An important aspect in comparing pCRFs and eCRFs that we have only touched upon in our questionnaires is the management of the delivery of drugs and placebo in pharmaceutical trials. Computerized treatment management programs that may be included in eCRF software enable investigators to streamline complex processes, including: managing the supply of medication to the centers even for long-term treatments, managing intricate protocols and overseeing product expirations. This system manages stock control and prevents waste, thus preventing breaks in inclusions due to supply ruptures and avoiding mistakes in treatment delivery to the patient.

\section{Conclusion}

This study examined eCRFs and pCRFs from the viewpoint of investigators and other important stakeholders. It found that eCRFs and pCRFs are used in studies with different patient numbers, center numbers and risk. The first ones are more advantageous in large, low-risk studies and gain support from a majority of stakeholders. Our findings also suggest that eCRF and pCRF may not be substitutes but complement each other with their own specific indications. The choice between paper and electronic CRF is a significant step in the design and execution of clinical studies; it should be discussed with the involved stakeholders and based on efficiency.

\section{Endnote}

${ }^{a}$ CDISC: standards of acquisition, exchange, submission and archive of clinical research data that enable information system interoperability to improve medical research.

\section{Additional files}

\author{
Additional file 1: Data collection form regarding studies \\ characteristics, variables and costs.
}

Additional file 2: Satisfaction questionnaire addressed to investigators. Additional file 3: Satisfaction questionnaire addressed to clinical research associates.

Additional file 4: Satisfaction questionnaire addressed to data managers.

Additional file 5: Analysis of investigators' satisfaction and preferences.

Additional file 6: Analysis of CRAs and DMs' satisfaction and preferences.

\section{Abbreviations}

eCRF: Electronic case report form; pCRF: Paper case report form;

CRAs: Clinical research associates; DM: Data managers; AP-HP: Assistance

Publique-Hôpitaux de Paris; CDISC: Clinical data interchange standards

consortium.

\section{Competing interests}

The authors declare that they have no competing interests.

\section{Authors' contributions}

$A L J, C A$ and IDZ conceived and designed the experiment. ALJ performed the experiment. $A L J$ and $C Q$ realized the acquisition and management of data, and analyzed the data. ALJ, CQ and IDZ wrote the paper. All authors read, commented and approved the final manuscript.

\section{Acknowledgements}

We wish to thank Nelly Biondi, Karen Berg Brigham, Meryl Darlington and Morgane Michel; Annick Tibi, Blandine Lehmann and Florence Barat from AGEPS (Agence Générale des Equipements et Produits de Santé); and the staff of the AP-HP CRUs who helped us to understand their work or responded to our questionnaires.

\section{The CompaRec investigators}

CRUs

P. Maison (AP-HP, CHU Henri Mondor, Unité de Recherche Clinique-Paris Est-Mondor, F-94010 Créteil, France), R. Serreau (AP-HP, Hôpital Saint Antoine, Unité de Recherche Clinique-Paris Est, F-75012 Paris, France), T. Simon

(AP-HP, Hôpital Saint Antoine, Unité de Recherche Clinique-Paris Est, F-75012 Paris, France), P. Aegerter (AP-HP, Hôpital Ambroise Paré, Unité de Recherche Clinique-Paris Île-de-France Ouest, F-92100 Boulogne, France), F. Tubach (AP-HP, Groupe hospitalier Bichat-Claude Bernard, Unité de Recherche Clinique-Paris Nord Val de Seine, F-75018 Paris, France), G. Chatellier (AP-HP, Hôpital Européen Georges Pompidou, Unité de Recherche Clinique-Paris Ouest, F-75015 Paris, France), L. Becquemont (AP-HP, Hôpital Bicêtre, Unité de Recherche Clinique- Paris Sud, F-94275 Le Kremlin-Bicêtre, France), A. Mallet (AP-HP, Hôpital de la Pitié-Salpêtrière, Unité de Recherche CliniquePitié Salpêtrière-Charles Foix, F-75013 Paris, France) and F. Maugard (AP-HP, Hôpital Saint Louis, DIRC/DRCD, F-75010 Paris, France);

Investigators

R. Yiou (AP-HP, CHU Henri Mondor, Service d'Urologie, F-94000 Créteil,

France), B. Godeau (AP-HP, CHU Henri Mondor, Service de Médecine Interne, F-94000 Créteil, France), P. Cesaro (AP-HP, CHU Henri Mondor, Service de Neurologie, F-94000 Créteil, France), A. Mekontso Dessap (AP-HP, CHU Henri Mondor, Service de Réanimation médicale, F-94000 Créteil, France), O. Bouillanne (AP-HP, Hôpital Émile-Roux, Service de Gérontologie, F-94450 LimeilBrévannes, France), G. Bobrie (AP-HP,Hôpital Européen Georges Pompidou, Service d'Hypertension Arterielle, F-75015 Paris, France), C. Faisy (AP-HP,Hôpital Européen Georges Pompidou, Service de Réanimation Médicale, F-75015 Paris, France), L. Bouadma (AP-HP, Groupe Hospitalier Bichat-Claude-Bernard, Service de Réanimation Médicale et Infectieuse, F-75018 Paris, France), S. Legrain (AP-HP, Groupe Hospitalier Bichat-Claude-Bernard, Service de Gériatrie, F-75018 Paris, France), F. Degos (AP-HP, Hôpital Beaujon, Service d'Hépatologie, F-92110 Clichy, France), D. Annane (AP-HP, Hôpital Pointcarré, Service de Réanimation Médicale, F-75010 Paris, France), B. Schlemmer (AP-HP, Hôpital Saint Louis, Service de Réanimation Médico-chirurgicale, F-92380 Garches, France), E. Thervet (AP-HP, CHU Necker-Enfants Malades, Service de Transplantation Rénale, 
F-75015 Paris, France ), R. Hankard (AP-HP, Hôpital Robert Debré, Comité de Liaison Alimentation Nutrition (CLAN), F-75019 Paris, France), C. Loirat (AP-HP, Hôpital Robert Debré, Service de Néphrologie Pédiatrique, F-75019 Paris, France), D. Bremond-Gignac (AP-HP, Hôpital Robert Debré, Service d'Ophtalmologie Pédiatrique, F-75019 Paris, France), N. Beydon (AP-HP, hôpital Armand-Trousseau, Unité fonctionnelle d'explorations fonctionnelles respiratoires, F-75012 Paris, France), E. Konofal (AP-HP, Hôpital Robert Debré, Centre pédiatrique des pathologies du sommeil, F-75019 Paris, France), Y.E. Claessens (Centre Hospitalier Princesse Grace, Département de Médecine d'Urgence, MC-98012 Monaco), G. Princ (AP-HP, Groupe Hospitalier Cochin-Saint-Vincent-de-Paul, Service de Stomatologie, F-75014 Paris, France), A.S. Rigaud (AP-HP, Hôpital Broca, Service de Gérontologie, F-75013 Paris, France), G. Cheron (AP-HP, CHU Necker-Enfants Malades, Service des urgences pédiatriques, F-75015 Paris, France), D. Joly (AP-HP, CHU Necker-Enfants Malades, Service de Nephrologie, F-75015 Paris, France), L. Guillevin (AP-HP, Groupe Hospitalier Cochin-Saint-Vincent-de-Paul, Service de médecine interne et Centre de Référence Maladies Rares, F-75014 Paris, France), N. CostedoatChalumeau (AP-HP, Hôpital de la Pitié-Salpêtrière, Service de Médecine Interne, F-75013 Paris, France) and D. Thabut (AP-HP, Hôpital de la Pitié-Salpêtrière, Service d'Hépato-Gastroentérologie, F-75013 Paris, France).

\section{Author details}

'Département de la recherche clinique et du développement, AP-HP, Groupe hospitalier Cochin Hôtel-Dieu, URC Économie de la Santé lle de France, F-75004 Paris, France. ${ }^{2}$ AP-HP, Hôpital Robert Debré, Unité d'Épidémiologie clinique, Groupe Hospitalier Robert Debré, 48, Bld Sérurier, F-75019 Paris, France. ${ }^{3}$ Université Paris Diderot, PRES Sorbonne Paris Cité, F-75019 Paris, France. ${ }^{4}$ Service de Santé Publique, AP-HP, Groupe hospitalier Albert Chenevier- Henri Mondor, F-94010 Créteil, France.

Received: 11 April 2013 Accepted: 31 December 2013

Published: 17 January 2014

\section{References}

1. Day S, Fayers P, Harvey D: Double data entry: what value, what price? Control Clin Trials 1998, 19:15-24.

2. Nahm ML, Pieper CF, Cunningham MM: Quantifying data quality for clinical trials using electronic data capture. PLOS ONE 2008, 3:e3049.

3. Kuchinke W, Ohmann C, Yang Q, Salas N, Lauritsen J, Gueyffier F, Leizorovicz A, Schade-Brittinger C, Wittenberg M, Voko Z, Gaynor S, Cooney M, Doran P, Maggioni A, Lorimer A, Torres F, McPherson G, Charwill J, Hellstrom M, Lejeune S: Heterogeneity prevails: the state of clinical trial data management in Europe - results of a survey of ECRIN centres. Trials 2010, 11:79.

4. El Emam K, Jonker E, Sampson M, Krleza-Jerić K, Neisa A: The use of electronic data capture tools in clinical trials: Web-survey of 259 Canadian trials. J Med Internet Res 2009, 11:e8.

5. Litchfield J, Freeman J, Schou H, Elsley M, Fuller R, Chubb B: Is the future for clinical trials internet-based? A cluster randomized clinical trial. Clin Trials 2005, 2:72-79.

6. Estellat C, Tubach F, Costa Y, Hoffmann I, Mantz J, Ravaud P: Data capture by digital pen in clinical trials: a qualitative and quantitative study. Contemp Clin Trials 2008, 29:314-323.

7. Brophy S, Burrows CL, Brooks C, Gravenor MB, Siebert S, Allen SJ: Internet-based randomised controlled trials for the evaluation of complementary and alternative medicines: probiotics in spondyloarthropathy. BMC Musculoskelet Disord 2008, 9:4.

8. Kush R, Alschuler L, Ruggeri R, Cassells S, Gupta N, Bain L, Claise K, Shah M, Nahm M: Implementing single source: the STARBRITE proof-of-concept study. J Am Med Inform Assoc 2007, 14:662-673.

9. Cole E, Pisano ED, Clary GJ, Zeng D, Koomen M, Kuzmiak CM, Seo BK, Lee Y, Pavic D: A comparative study of mobile electronic data entry systems for clinical trials data collection. Int I Med Inform 2006, 75:722-729.

10. Brandt CA, Argraves S, Money R, Ananth G, Trocky NM, Nadkarni PM: Informatics tools to improve clinical research study implementation. Contemp Clin Trials 2006, 27:112-122.

11. Galliher JM, Stewart TV, Pathak PK, Werner JJ, Dickinson LM, Hickner JM: Data collection outcomes comparing paper forms with PDA forms in an office-based patient survey. Ann Fam Med 2008, 6:154-160.
12. Herzberg S, Rahbar K, Stegger L, Schäfers M, Dugas M: Concept and implementation of a computer-based reminder system to increase completeness in clinical documentation. Int J Med Inform 2011, 80:351-358.

13. Thwin SS, Clough-Gorr KM, McCarty MC, Lash TL, Alford SH, Buist DSM, Enger SM, Field TS, Frost F, Wei F, Silliman RA: Automated inter-rater reliability assessment and electronic data collection in a multi-center breast cancer study. BMC Med Res Method 2007, 7:23.

14. Walther B, Hossin S, Townend J, Abernethy N, Parker D, Jeffries D: Comparison of Electronic Data Capture (EDC) with the standard data capture method for clinical trial data. PLOS ONE 2011, 6:e25348.

15. Journot V, Pignon J-P, Gaultier C, Daurat V, Bouxin-Métro A, Giraudeau B, Preux P-M, Tréluyer J-M, Chevret S, Plättner V, Thalamas C, Clisant S, Ravaud P, Chêne G: Validation of a risk-assessment scale and a risk-adapted monitoring plan for academic clinical research studies-the Pre-Optimon study. Contemp Clin Trials 2011, 32:16-24.

16. Paul J, Seib R, Prescott $T$ : The Internet and clinical trials: background, online resources, examples and issues. J Med Internet Res 2005, 7:e5.

17. Dorman K, Saade GR, Smith H, Moise KJ: Use of the world wide web in research: randomization in a multicenter clinical trial of treatment for twin-twin transfusion syndrome. Obstet Gynecol 2000, 96:636-639.

18. Pavlović I, Kern T, Miklavcic D: Comparison of paper-based and electronic data collection process in clinical trials: costs simulation study. Contemp Clin Trials 2009, 30:300-316.

19. Marks RG: Validating electronic source data in clinical trials. Control Clin Trials 2004, 25:437-446.

20. Lallas CD, Preminger GM, Pearle MS, Leveillee RJ, Lingeman JE, Schwope JP, Pietrow PK, Auge BK: Internet based multi-institutional clinical research: a convenient and secure option. J Urol 2004, 171:1880-1885.

21. López-Carrero C, Arriaza E, Bolaños E, Ciudad A, Municio M, Ramos J, Hesen W: Internet in clinical research based on a pilot experience. Contemp Clin Trials 2005, 26:234-243.

22. Welker JA: Implementation of electronic data capture systems: barriers and solutions. Contemp Clin Trials 2007, 28:329-336.

23. Ventres W, Kooienga S, Vuckovic N, Marlin R, Nygren P, Stewart V: Physicians, patients, and the electronic health record: an ethnographic analysis. Ann Fam Med 2006, 4:124-131.

24. Lium J-T, Tjora A, Faxvaag A: No paper, but the same routines: a qualitative exploration of experiences in two Norwegian hospitals deprived of the paper based medical record. BMC Med Inform Decis Mak 2008, 8:2.

25. Barber JA, Thompson SG: Analysis of cost data in randomized trials: an application of the non-parametric bootstrap. Stat Med 2000, 19:3219-3236.

26. Marks RG, Conlon M, Ruberg SJ: Paradigm shifts in clinical trials enabled by information technology. Stat Med 2001, 20:2683-2696.

27. Weber BA, Yarandi H, Rowe MA, Weber JP: A comparison study: paper-based versus web-based data collection and management. Appl Nurs Res 2005, 18:182-185.

28. Bart T: Comparison of electronic data capture with paper data collection - Is there really an advantage? In business briefing. PharmaTech 2003, 2003:1-4 [World Markets Series].

doi:10.1186/1471-2288-14-7

Cite this article as: Le Jeannic et al: Comparison of two data collection processes in clinical studies: electronic and paper case report forms. BMC Medical Research Methodology 2014 14:7. 